\title{
The transfer of energy from the solar-space power station to the Earth
}

\author{
William Kaganov ${ }^{1 *}$ \\ ${ }^{1}$ Moscow Technological University - MIREA, Russia
}

\begin{abstract}
The resulting problem in the transmission of electrical energy from space to the Earth by means of microwave electromagnetic waves is discussed. The main parameters and principles for constructing the space and ground segments of such a solar power plant are given.
\end{abstract}

\section{The essence of the problem}

Solar power plants (SP) are the leading direction in alternative electric power industry, accounting for about $6 \%$ in the electric power balance of the leading countries in the world.

The specific power of solar radiation in outer space is $1.4 \mathrm{~kW} / \mathrm{m}^{2}$ or $12,000 \mathrm{kWh} / \mathrm{m}^{2}$ of energy per year. Due to the reflection of sunlight in the atmosphere, the first indicator in clear weather in the equatorial zone of the Earth is reduced to $1 \mathrm{~kW} / \mathrm{m}^{2}$, and in other areas to an even smaller value. Approximately the average daily value of this indicator for different regions of the Earth does not exceed $0.3-0.4 \mathrm{~kW} / \mathrm{m}^{2}$.

Taking into account all the factors (atmospheric dispersion, weather effect, daily and annual indicators of the Earth's surface illumination) with the efficiency of solar cells $20 \%$ [1,2], the conversion of solar energy into electrical energy is $1 \%$, i.e. the specific energy value per year is $120 \mathrm{kWh} / \mathrm{m}^{2}$.

The view of such a small value of this parameter was the birth of a proposal for the removal of SPS into outer space where the influence of the atmosphere is excluded, and intensive irradiation of solar batteries occurs continuously throughout the day and the whole year [3]. Since then, there have been practically no publications on the problem submitted. However, at the present time, in connection with the appearance of powerful microwave transistors, with the help of which it is possible to convert the energy of solar batteries into microwave radiation, the idea of building a solarspace power plant becomes technically feasible. As calculations show, the efficiency of such solar-space power stations (SSP) can exceed the ground-based ones by $10-20$ times and make up $1200 \mathrm{~kW}-\mathrm{h} / \mathrm{m}^{2}$ of energy per year. All the data are summarized in Table 1.

One of the technical problems in the implementation of the idea for the creation of SSP is the transfer of the energy it generates to the Earth. The general scheme of SSPS, in which energy from space to the Earth is transmitted by microwave radiation, is shown in Fig. The scheme includes two segments: space and ground. Consider the principles of their construction and basic parameters

Table 1. Comparison of two types of solar power plants

\begin{tabular}{|l|l|l|l|}
\hline $\begin{array}{l}\text { Location: } \\
\text { Solar } \\
\text { Batteries }\end{array}$ & $\begin{array}{l}\text { Specific } \\
\text { Power } \\
\text { Solar } \\
\text { Radia- } \\
\text { tion }\end{array}$ & $\begin{array}{l}\text { Specific } \\
\text { amount of } \\
\text { radiated } \\
\text { solar ener- } \\
\text { gy per year }\end{array}$ & $\begin{array}{l}\text { Specific } \\
\text { amount Elec- } \\
\text { trical Energy } \\
\text { per year with } \\
\text { EFFICIENCY } \\
=20 \%\end{array}$ \\
\hline $\begin{array}{l}\text { Dimen- } \\
\text { sionality }\end{array}$ & $\mathrm{kW} / \mathrm{m}^{2}$ & $\mathrm{~kW}-\mathrm{h} / \mathrm{m}^{2}$ & $\mathrm{~kW}-\mathrm{h} / \mathrm{m}^{2}$ \\
\hline In space & 1,4 & $\begin{array}{l}12000 \\
(100 \%)\end{array}$ & $1200(10 \%)$ \\
\hline On Earth & $0,3-1$ & $600(5 \%)$ & $120(1 \%)$ \\
\hline
\end{tabular}

\section{Space segment of the SSP}

This segment includes:

- solar batteries, facing their flat surface to the Sun; - a certain number of microwave semiconductor generators that convert the direct current energy generated by solar batteries into microwave electromagnetic oscillations;

- the same number of radiators forming a phased antenna array directed towards the Earth; - two extreme systems of automatic control, the first of which provides maximum consumption of solar energy batteries, the second one - the continuous direction of the antenna array's directional pattern to the desired place on the Earth, where the receiving antenna is located.

The first of which provides maximum consumption of solar energy batteries, the second one - the continu-

*Corresponding author: Kaganovwil@yandex.ru 
ous directivity pattern of the antenna array's directional pattern to the desired place on the Earth, where the receiving antenna is located.

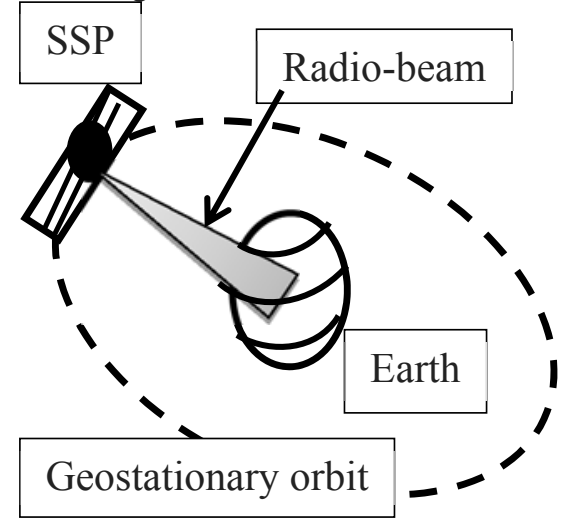

Fig.1. The scheme of transmission of microwave energy from space to Earth.

The general scheme for the transmission of microwave energy produced in a geostationary orbit to Earth is shown in Fig. 2, where the following designations were adopted: 1- solar array, 2- satellite in geostationary orbit, 3-phased array antenna, 4 - a set of receiving terrestrial antennas, DA - their total diameter. H- is the height of the antenna array above the Earth. The signal frequency emitted by the phased array, $\mathrm{f}=6 \mathrm{GHz}$, i.e. the wavelength $\lambda=5 \mathrm{~cm}$.

At $\mathrm{H}=36 \bullet 10^{6} \mathrm{~m}$ (more accurately $\mathrm{H}=35,786 \bullet$ $10^{6} \mathrm{~m}$ - height of the geostationary orbit), and $\mathrm{D}_{\mathrm{A}}=25$ - $10^{3} \mathrm{~m}$, we obtain for the angle of the antenna pattern opening, located on the space object,

$$
\alpha=2 \cdot\left(\frac{180}{\pi}\right) \bullet \operatorname{atan}\left(D_{\mathrm{A}} / 2 H\right)=0,044^{0}
$$

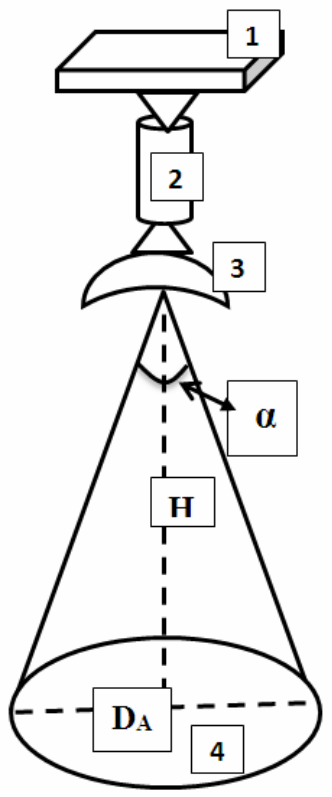

Fig.2. The scheme for determining the antenna's angle of directivity
The very diagram of the direction in one plane of the antenna array on two scales is shown in Fig. 3, where the angle is in degrees. Angle $\alpha=\Delta \Theta=0,044^{0}$ is the width of the ray of the diagram of the direction of the 0.7 level with respect to the maximum value of the field strength.

To obtain such a directional diagram with a wavelength $\lambda=5 \mathrm{~cm}$ in each line of a flat phased array antenna, 1000 emitters should be located, and their total number is a one million. As the radiators of a phased array, it is possible to use micro strip antennas of the Vivaldi type (Fig. 4) [4]. The distance between two neighboring radiators is $\mathrm{b}=\lambda=5 \mathrm{~cm}$.
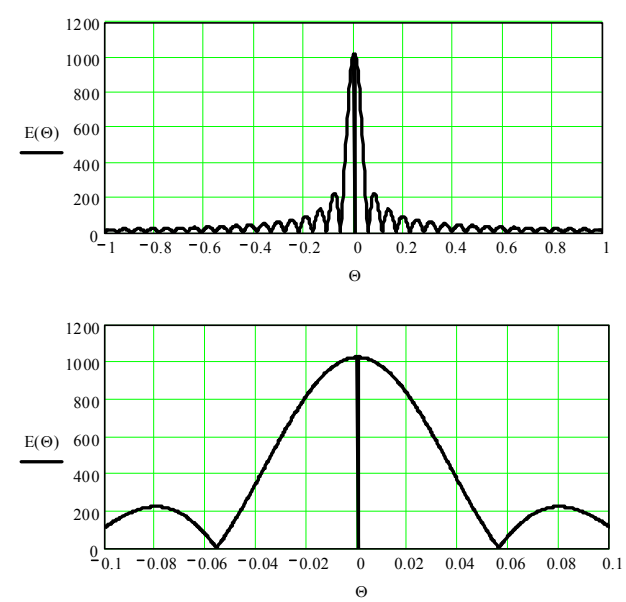

Fig. 3. Directivity diagram

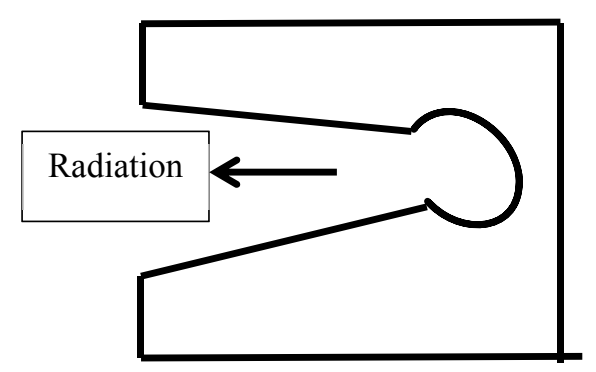

Fig.4. Outward visible Vivaldi

\section{The terrestrial segment of the SSPP and the main parameters of the SSP}

The ground segment includes:

- the antenna array receiving the microwave signal of the space segment;

- an ensemble of detectors that convert the received microwave signal into direct current;

- microprocessor system for automatic control and monitoring of operation of all elements of the facility.

When calculating the SPS-Earth radio link, it is necessary to take into account:

- the power and frequency of the microwave signal supplied to each of the radiators of the CFA,

- the total number of such emitters,

- the dimensions of the receiving terrestrial antenna, 
- the following signal power losses in the radio link due to the lobes of the transmitting and receiving antennas.

Attenuation of the microwave signal during passage through the atmosphere loss when detecting a signal received by a receiving antenna, the efficiency of the microwave generator connected to the radiator, the efficiency of solar cells.

The results of the calculation, carried out taking into account the listed factors with $20 \%$ efficiency of solar cells, a total emitter of 1 million and two values of the microwave power supplied to each radiator at $150 \mathrm{~W}$, are shown in Table 2.

Table 2. The main parameters of the SSP

\begin{tabular}{|l|c|}
\hline \multicolumn{1}{|c|}{ Parameter } & Value \\
\hline $\begin{array}{l}\text { Total power of solar cells in the } \\
\text { X-ray segment }\end{array}$ & $430 \mathrm{MW}$ \\
\hline $\begin{array}{l}\text { The area of the solar cell com- } \\
\text { plex of the space segment }\end{array}$ & $550 * 55 \mathrm{~m}^{2}$ \\
\hline $\begin{array}{l}\text { Microwave power of one radia- } \\
\text { tor }\end{array}$ & $150 \mathrm{~W}$ \\
\hline $\begin{array}{l}\text { The total power of the micro- } \\
\text { wave signal emitted from the } \\
\text { space segment }\end{array}$ & $150 \mathrm{MW}$ \\
\hline $\begin{array}{l}\text { Total DC power produced by the } \\
\text { ground segment }\end{array}$ & $100 \mathrm{MW}$ \\
\hline $\begin{array}{l}\text { The density of the microwave } \\
\text { energy flux near the Earth }\end{array}$ & $\begin{array}{c}200 \mathrm{MW} / \\
\mathrm{m}^{2}\end{array}$ \\
\hline
\end{tabular}

\section{Microwave generators feeding the antenna array, and their synchronization}

The microwave transistor generators with a frequency of $6 \mathrm{GHz}$ in the space segment can be powered directly from solar panels with a voltage of 20 to $30 \mathrm{~V}$. Note that in the microwave range, two types of tracers with a power of up to $25 \mathrm{~W}$ are produced: field gallium arsenide (GaAs) and "gallium nitride Silicon (GaN-on-Si). [5].High reliability and durability, low value of the supply voltage (up to $30 \mathrm{~V}$ ) predetermines their use as generators in the space segment of the SSP.

Schemes and the device of microwave transistor generators are considered, for example, in [4]. In the 1 st version of the SSP (i.e with a microwave power supply feeding to one radiator, at $15 \mathrm{~W}$ ), such a generator can include two stages: an auto generator and an amplifier. In the case of the 2 nd variant, that is, at a power of $150 \mathrm{~W}$, they should be supplemented with a scheme for summing the powers of the four transistors to obtain a microwave power of $150 \mathrm{~W}$.

\section{Synchronization of auto generators}

As a result of the interaction between all auto generators, when certain conditions are met, a single rhythm of operation is established in the system, which means that the frequencies of all auto-oscillations are equal and the system is put into synchronization mode. In this case, the system can be multistage with integration at the 1st level, for example, at the first level 1000 auto generators, on the second - 10000 where 1 is an auto generator, 2 is a microwave power amplifier.

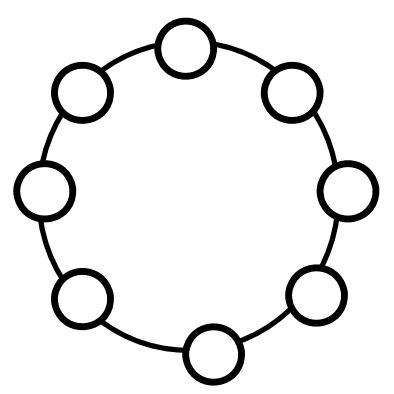

Fig.5. Structural scheme of synchronization of microwave oscillators

According to the scheme in Fig. 5, each of the auto generators interacts with two neighboring ones, which should be taken into account in the compilation of differential equations describing the operation of the system as a whole and consisting of $\mathrm{N}$ equationsaccording to the number of sources of oscillations.

$$
\begin{aligned}
& \frac{d^{2} u_{1}}{d \tau^{2}}-\mu_{1} \Phi_{1}\left(u_{1}\right) \frac{d u_{1}}{d \tau}+\Omega_{1} u_{1}+\sum_{\mathrm{M}_{2}}^{\mathrm{M}_{2}} k_{i} u_{i}=0 \\
& \frac{d^{2} u_{2}}{d \tau^{2}}-\mu_{2} \Phi_{2}\left(u_{2}\right) \frac{d u_{2}}{d \tau}+\Omega_{2} u_{2}+\sum_{\mathrm{M}_{3}}^{\mathrm{M}_{4}} k_{i} u_{i}=0, \\
& \frac{d^{2} u_{\mathrm{n}}}{d \tau^{2}}-\mu_{\mathrm{n}} \Phi_{\mathrm{n}}\left(u_{\mathrm{n}}\right) \frac{d u_{\mathrm{n}}}{d \tau}+\Omega_{\mathrm{n}} u_{\mathrm{n}}+\sum_{\mathrm{M}_{\mathrm{n}-1}}^{\mathrm{M}_{\mathrm{n}}} k_{i} u_{i}=0,
\end{aligned}
$$

where $\Phi \mathrm{i}\left(u_{i}\right)$ is a nonlinear function, $k_{\mathrm{ii}}$ - is the coupling coefficient of the auto generator with the other two, $\Omega_{\mathrm{i}}$ - is the ratio of the deviation of the natural frequency of the i-th self-oscillator in the autonomous mode of operation to the frequency of self-oscillations in the system.

To coincide the initial phases of oscillations of synchronized oscillators, the distance between them should be equal to an integer number of wavelengths $\lambda$. One of the higher power generators in such a circuit can be the master. Computer simulation, conduct with 16 auto generators included in the system, showed that the initial discrepancy of their frequencies can reach $5 \%$, one hundred does not prevent their entry into synchronism.

\section{Remote charging of batteries unmanned aerial vehicle}

In addition to the considered option of remote transmission of electrical energy in outer space, the solution 
of this problem is important for some projects of today.

These include, in particular, remote charging of batteries unmanned aerial vehicles. The ground station such a system includes a microwave generator with a frequency of $2.45 \mathrm{GHz}$, a power of $1 \mathrm{~kW}$ from the mass-produced microwave oven; parabolic antenna with a diameter of $3 \mathrm{~m}$ and the device of its guidance on an unmanned aerial vehicle, hovering at a height of up to $100 \mathrm{~m}$.

The equipment on board the unmanned vehicle includes: a phased array antenna with a number of $32 \times 32$ emitters, microwave detectors attached to these emitters, and a rectifier connected to the battery to charge it.

Thus, it is possible to carry out remote charging of batteries by an unmanned aerial vehicle without landing on the Earth, which is extremely necessary in many cases.

\section{Conclusion}

1. The conducted comparative analysis of two types of solar power plants ground and space - shows unquestionable advantages in terms of the energy performance of a power plant of the second type.

2. Within the framework of the first stage of the implementation of this project, it is necessary to solve the problem of today: remote charging of unmanned vehicle batteries.

\section{References}

1. K. Chopra, S. Das Thin-film solar cells (M. Mir, 1986).

2. T. Byers 20 designs with solar elements (M: Mir, 1988).

3. P.E. Glezer The Potential of Satellite Solar Power (Proceedings IEEE, v.65).

4. S.E. Banks, et al., Radio engineering and electronics, №12, p.52-63, (2015).

5. Electronics news, №7, p.5-20, (2015). 